\title{
الإطار القانوني للإيجاب والقبول في الصفقات العمومية
}

\section{The legal framework for the acceptance and affirmation of public deals}

\author{
تاريخ الاستلام : 2020/02/20؛ تاريخ القبول : 2020/07/29
}

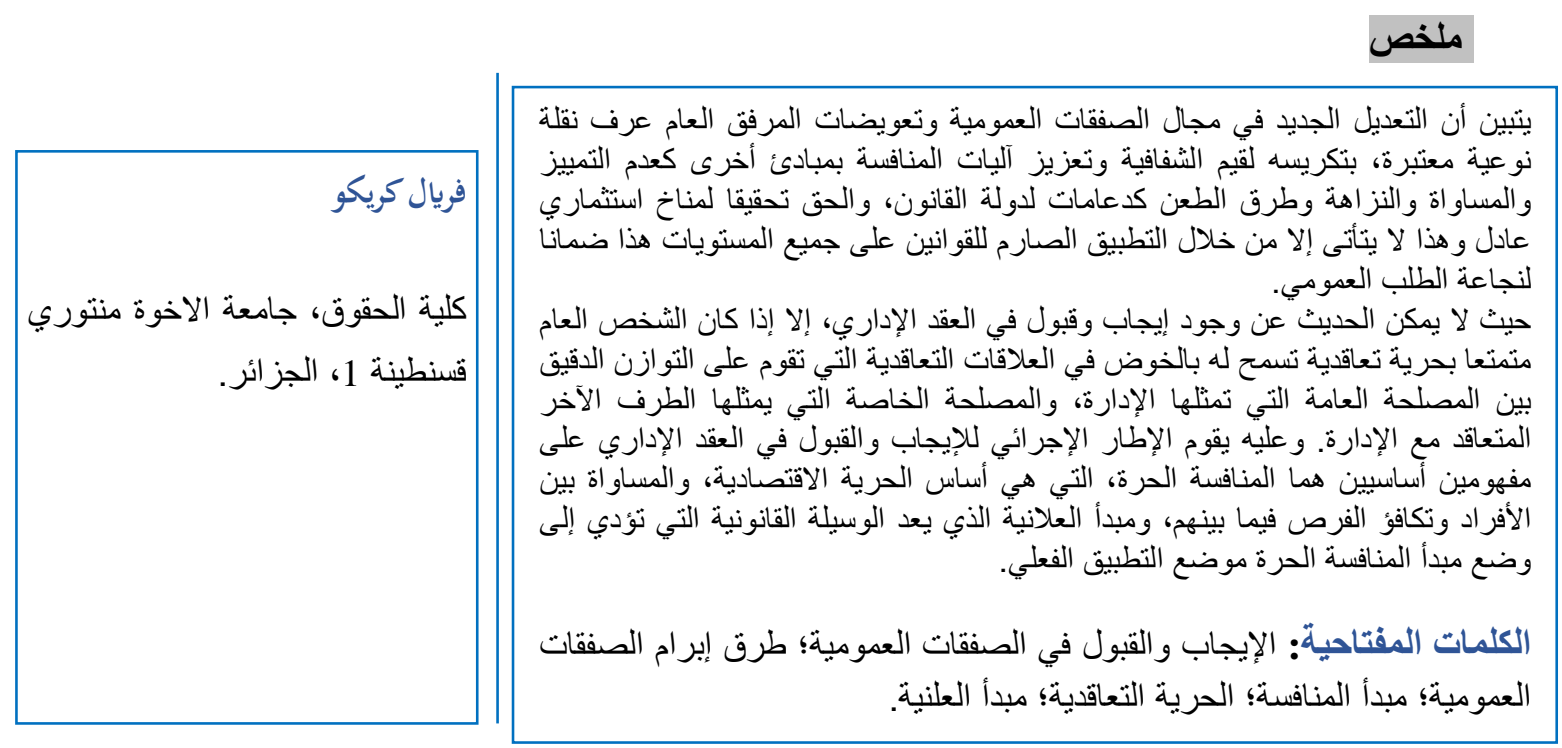

\section{Abstract}

It appears that the new amendment in the area of public deals and public utility delegations has marked a significant paradigm shift,through devoting it to the values of transparency and the promotion of competition mechanisms with other principles of non-discrimination, equality, integrity and methods of appeal as pillars of the state of law and right, in order to achieve a fair investment climate which will not be realized only by the strict application of the laws on all the levels to ensure the efficacy of public demand .

As it is not possible to talk about the presence of acceptance and affirmation in the administrative contract unless the public person has contractual freedom that allows him to enter into contractual relations based on the delicate balance between common interest represented by the administration and the other interest represented by the other chambers contracted with the administration. Therefore, the procedural framework for affirmation and acceptance in the administrative contract is based on two fundamental concepts (the deal) and they are: the free competition, which is the basis of economic freedom, and the equivalence between individuals and equal opportunities between them. In addition to the standard of openness, which is the legal way that leads to putting the principle of free competition into practice.

Keywords: The acceptance and affirmation in public deals; Ways of concluding public deals; Principle of competition ;Contractual Freedom ;Principle of Publicity .

\section{Résumé}

Il apparaît que le nouvel amendement dans le domaine des marchés publics et des délégations d'utilité publique a marqué un changement de paradigme significatif, en le consacrant aux valeurs de transparence et de promotion des mécanismes de concurrence avec d'autres principes de non-discrimination, d'égalité, d'intégrité et de méthodes d'appel en tant que piliers de l'état de droit et des lois, afin de parvenir à un climat d'investissement équitable qui ne sera pas réalisé uniquement par l'application stricte des lois à tous les niveaux pour assurer l'efficacité de la demande publique.

Comme il n'est pas possible de parler de la présence d'acceptation et d'affirmation dans le contrat administratif à moins que la personne publique ne dispose d'une liberté contractuelle lui permettant de nouer des relations contractuelles fondées sur le fragile équilibre entre l'intérêt commun représenté par l'administration et l'autre intérêt représenté par les autres chambres contractées avec l'administration. Par conséquent, le cadre procédural d'affirmation et d'acceptation dans le contrat administratif repose sur deux concepts fondamentaux (l'accord) et ce sont: la libre concurrence, qui est la base de la liberté économique, et l'équivalence entre les individus et l'égalité des chances entre eux. En plus de la norme d'ouverture, qui est la voie légale qui conduit à la mise en pratique du principe de libre concurrence.

Mots clés: L'acceptation et l'affirmation dans les marchés publiques; ;Façons de conclure des marchés publiques;Principe de compétition;Liberté contractuelle;Principe de Publicité .

* Corresponding author, e-mail: krikouferiel@gmail.com 


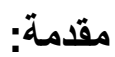

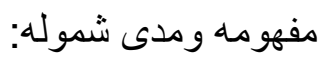
يتكون الإطار القانوني للإيجاب والقبول في في العقد الإداري عامة من كل الآليات

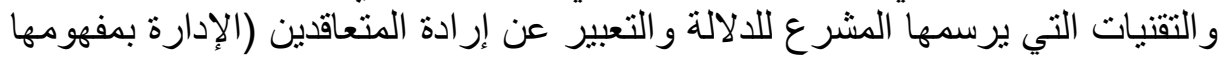

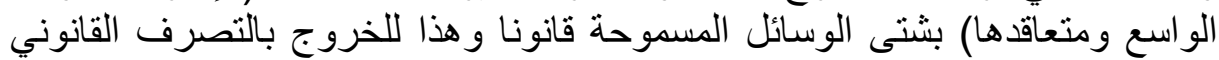

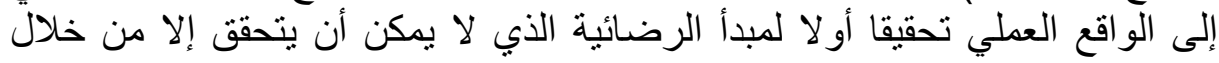

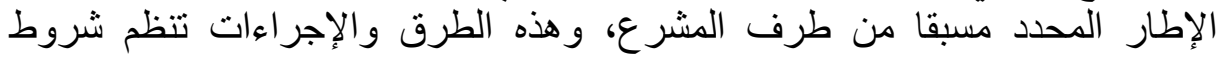

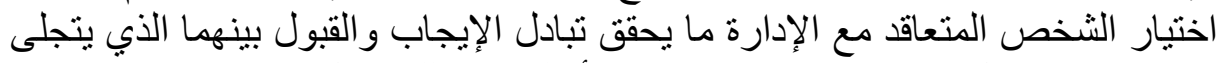
ويظهر من خلال العقد الإداري عامة ومبدأ الثفافية للوصول الإداد بالصفقة إلى مبنغاها

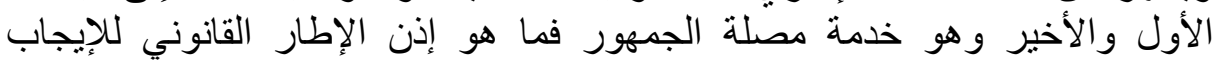
و القبول في الصفقة العمومية.

المبحث الأول: قواعد إبرام الصفقات العمومية في ضوء المرسوم الرئاسي

لقد صدر المرسوم الرئاسي 247/15 بتاريخ 26 سبتمبر 2015 معلنا عن تتظيم جديد لصفقات العمومية وحمل هذا الأخير 220 مادة ونشير فئرئ في العدد 50 من من الجريدة

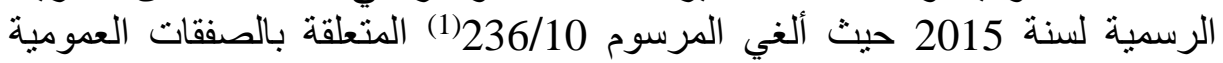

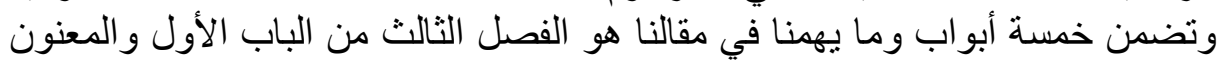

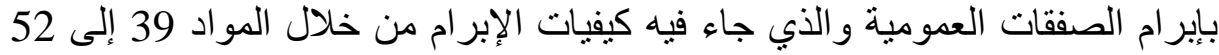

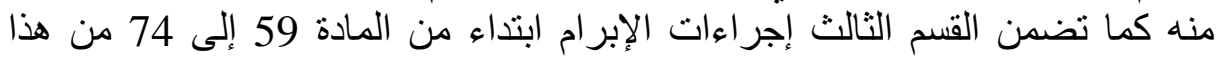

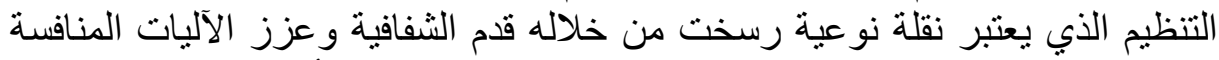

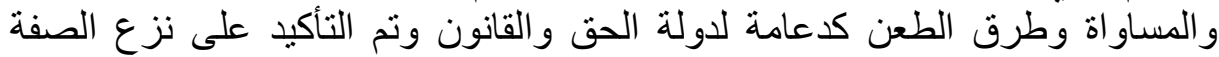

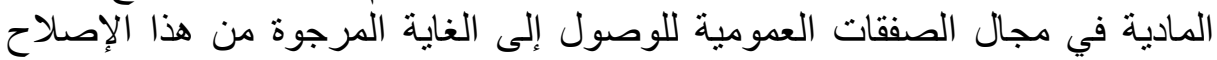

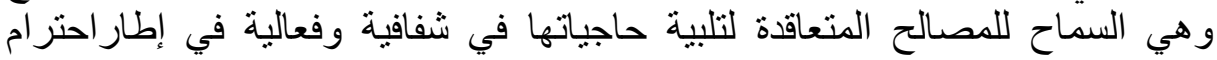

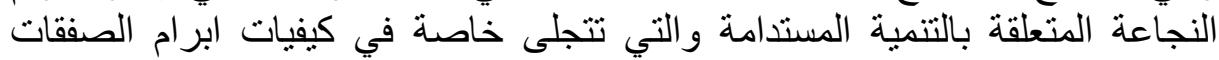

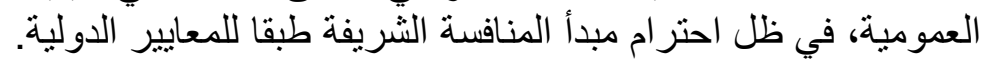

\section{المطلب الأول: كيفيات إبرام الصفقات العمومية:}

أوضح المشرع الجزائري بموجب أحكام المرسوم الرئاسي 15-247 وتحديدا الفصل إنها

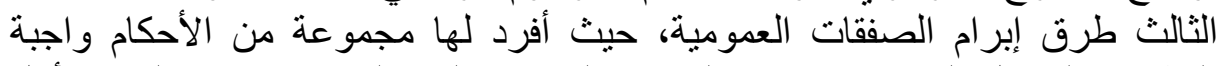

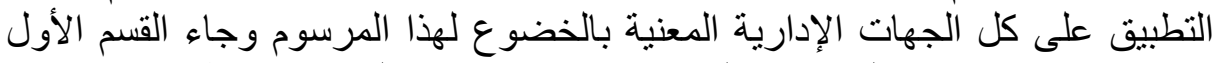

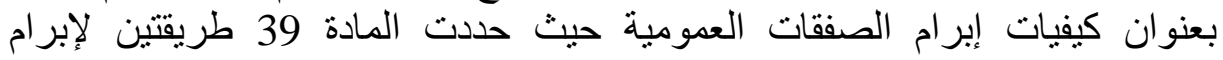
الصفقات العمو مية وهما:

(2) $15 / 247$

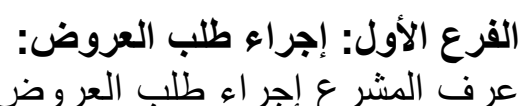
كالآتي:

- كالب: طلب العروض هو إجراء يستهدف الحصول على عروض من عدة متعهدين

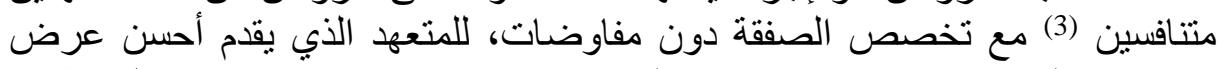

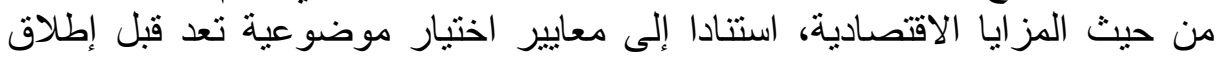
الإجراء. - مان. 
أما عن الحالات عدم جدوى إجر اء طلب العروض فتتلخص فيما يلي:

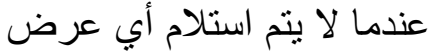

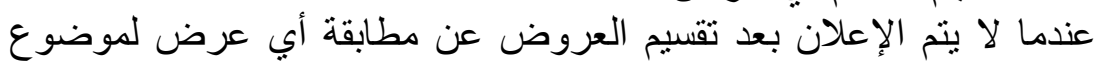
الصفقة ولمحتوى دفتر الثروط.

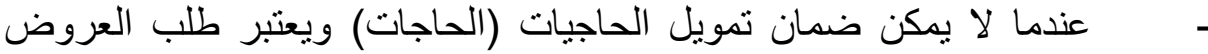

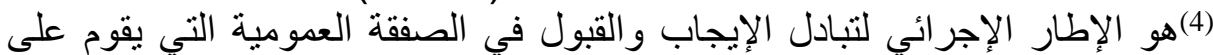
مبادئ المنافسة المفتوحة و العلانية.

الفرع الثاني: أشكال طلب القروض: إن للصفقات العمومية صلة الثيكات وطيدة بالخزينة العمومية وبمخططات التنمية وتكريسا

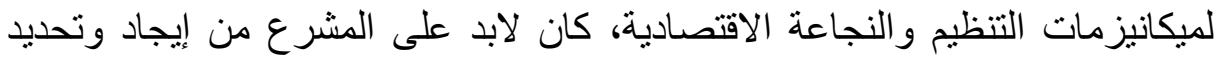

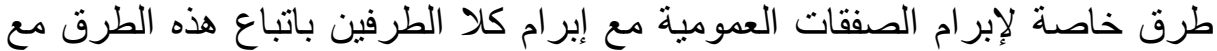

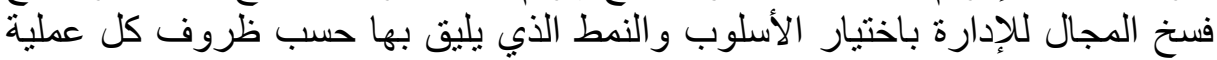

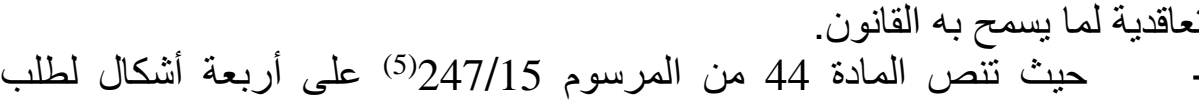
العروض المفتوح Appel d'offres ouvert

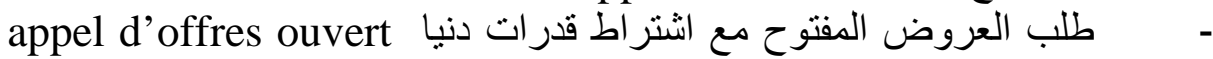
avec exigence de capacités minimales - - ملب العروض المحدود Appel d’offre restreint -

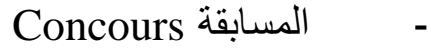

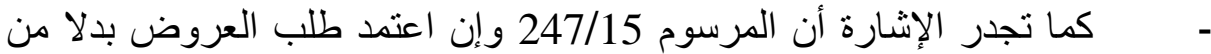

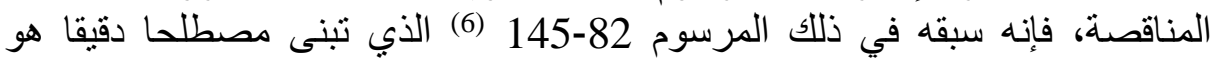
الدعوة للمنافسة وهو ما أنثارت إليه اليه المو اد 26 وما يليها.

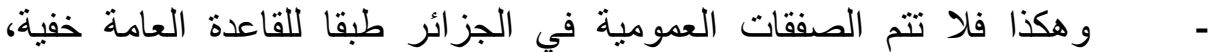

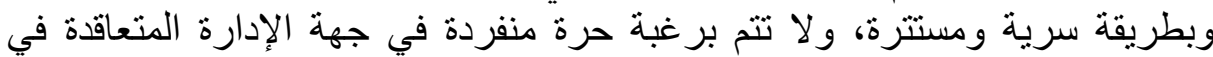

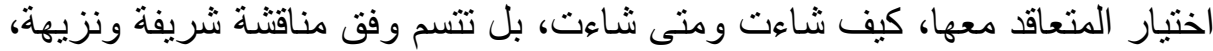

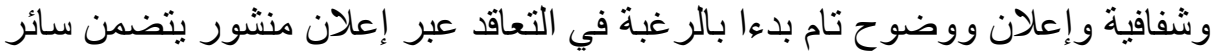

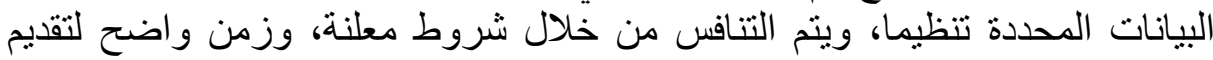

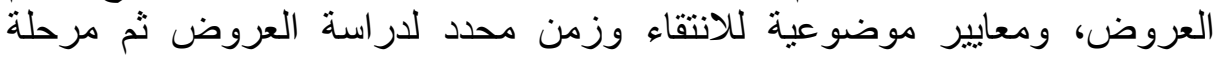

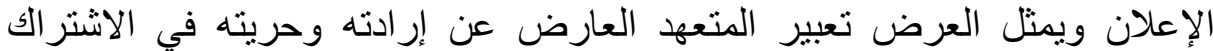
بطلب العروض عن طريق معايير المفاضلة بين العارضين التي لم تعد تؤسنس اليون اليوم

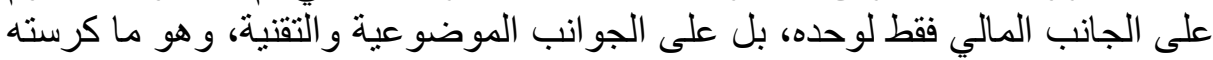

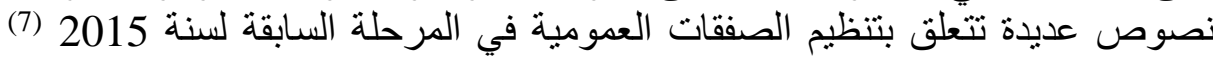
هذا باستثناء مرحلة الأمر 67-90 و الذي جعل المناقصة تقوم على أساس المعيار

- ـ مكذا صدر المرسوم 247/15 الذي اعتمد مصطلح طلب العروض بدل

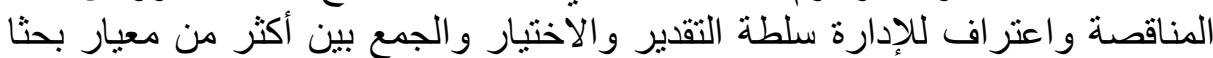

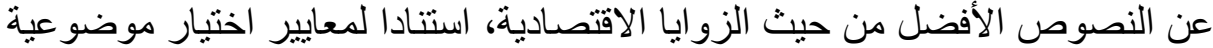

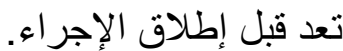

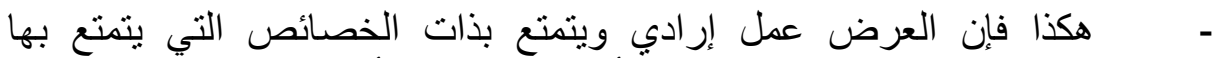

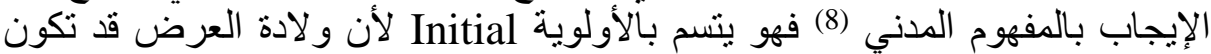
بداية للتعبير في شبكة العلاقات و المعاملات القانونية ولكن ليس بين الأفراد كما هو لاده

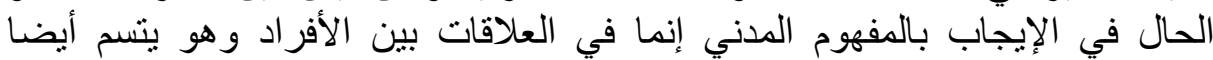

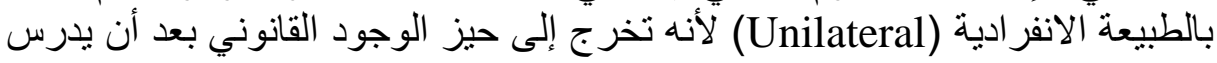


العارض مركزه القانوني و الإقتصادي، فيقرر أن يتقدم إلى الإدارة بهذا العرض وضئه وفقا

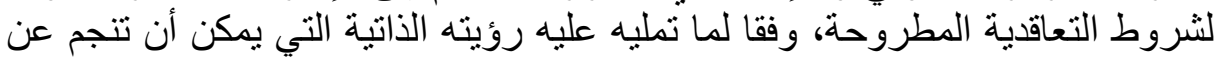

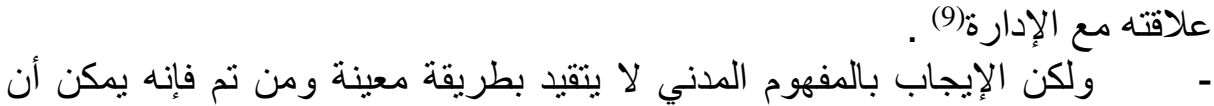

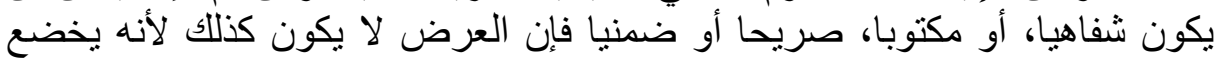

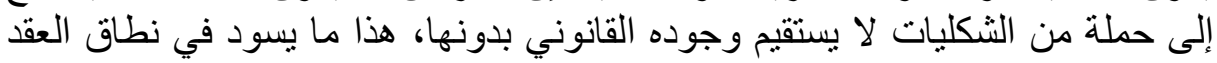

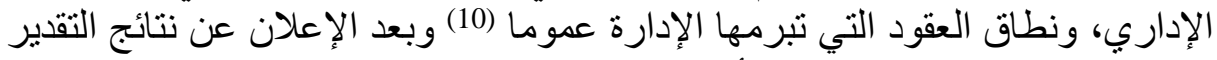

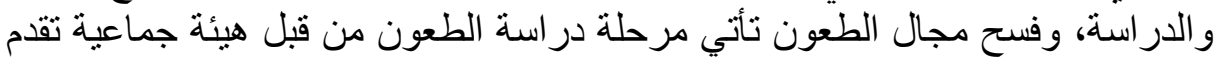

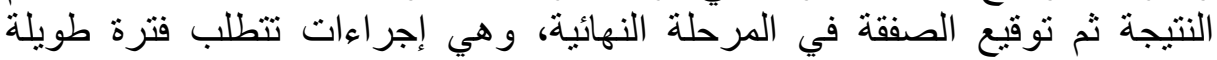

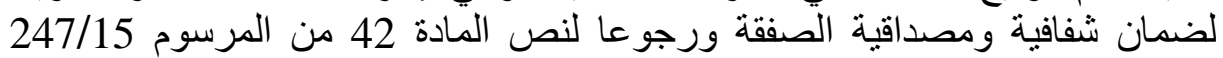

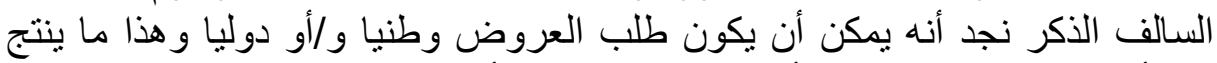

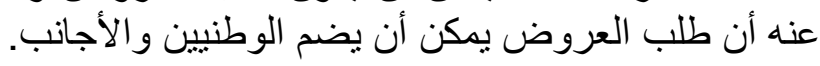

$$
\text { المطلب الثاني: إجراء التراضي: }
$$

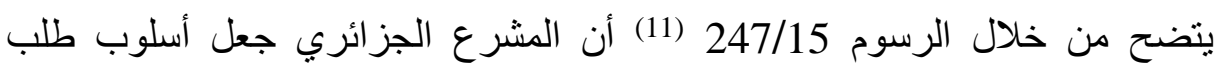

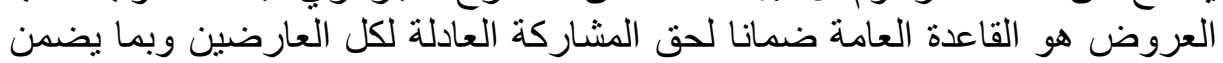

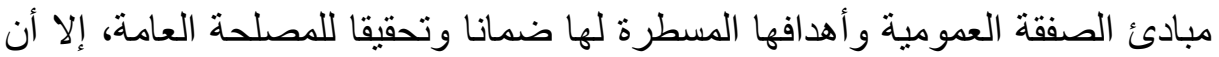

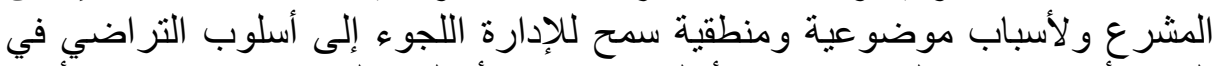

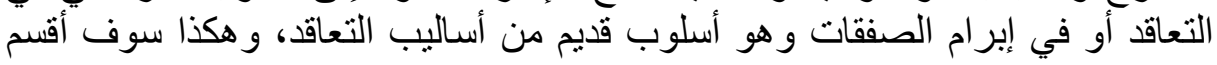

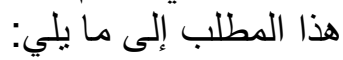

$$
\text { الفرع الأول: تعريف التراضي: }
$$

عرفت المادة 41 من المرسوم 247/15 بأن " التراضي هو إجراء تخصيص صفي صفقة

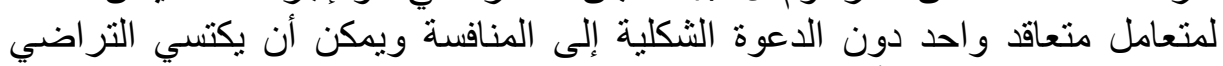

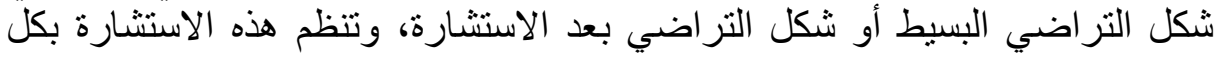

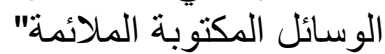

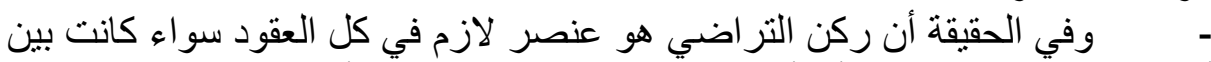

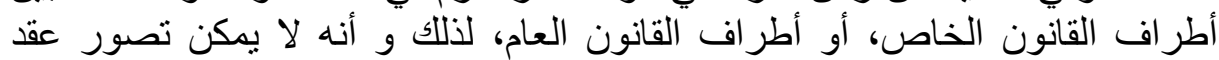

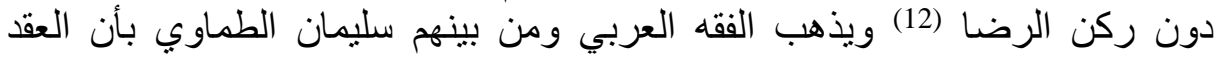

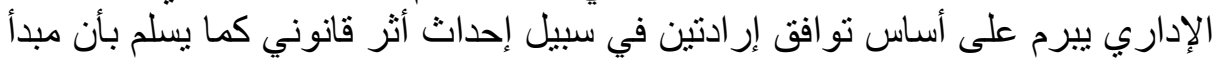

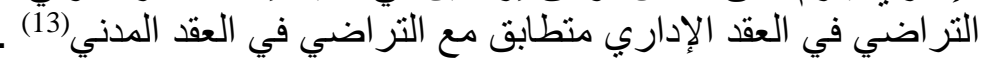

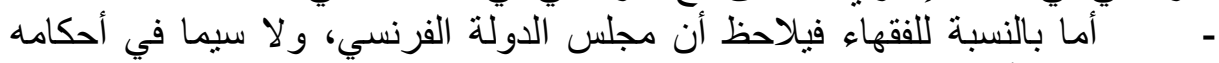

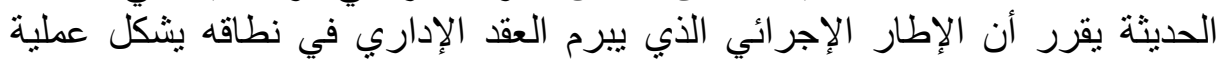

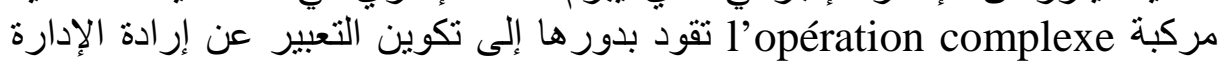

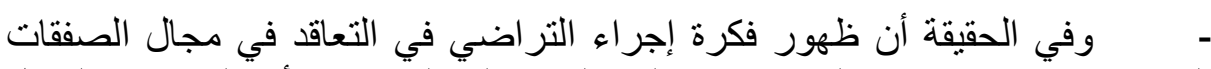

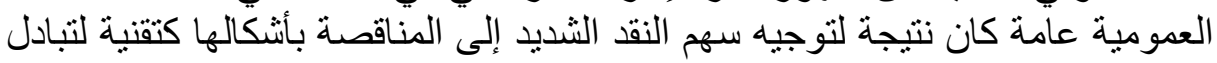
الإيجاب و القبول، وقد يتمثل نيجة هذا النقد فيما يلي:

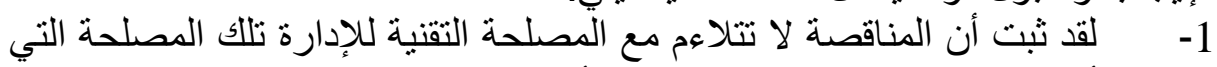

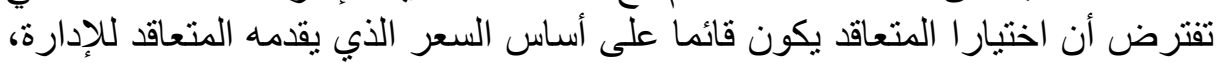


بمعنى أن اعتبار المتعاقد معاونا للإدارة في تسبير المرفق العام، لا يمكن أن ينسجم مع تقنية المناقصة وتلقائيتها (15). 2-

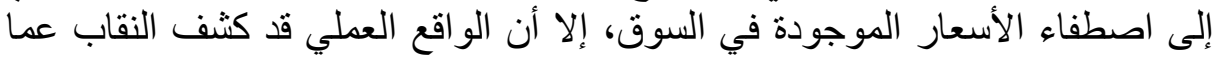

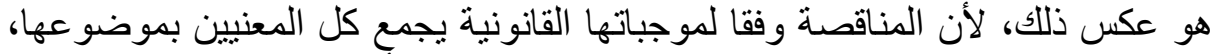

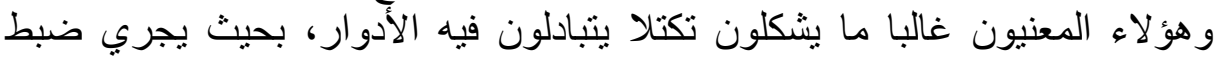

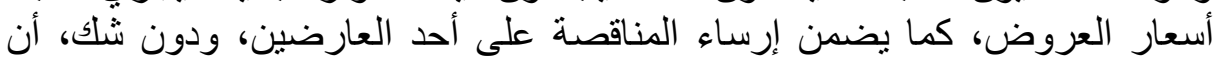

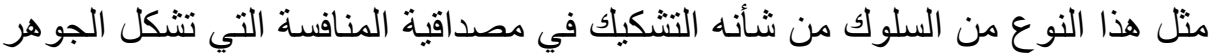

الذي حرص المشرع عنى الى مر اعاته للوصول إلى إلى أفضل الأسعار (16).

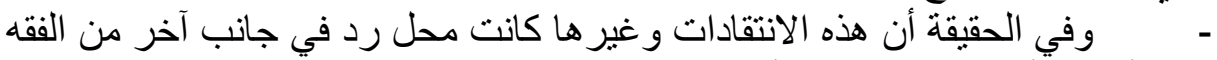

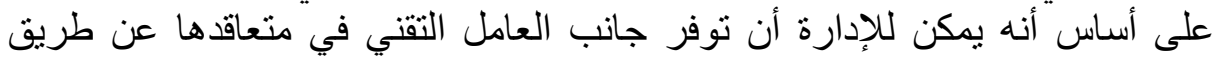

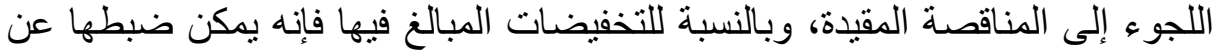

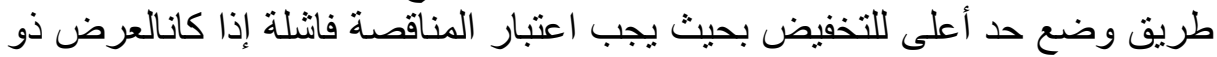

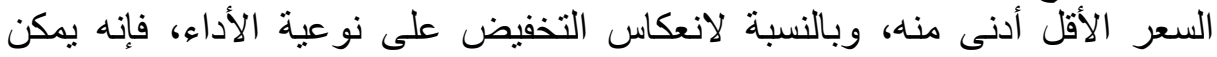

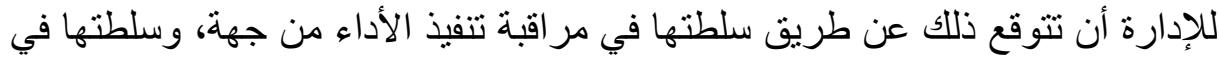
ترتيب جز اءات تعاقدية من جهة أخرى.

الفرع الثاني: أشكال التراضي وحالاته:

كرس المشرع أسلوب التراضي(17) معترفا للمصلحة المتعاقدة بقدم اتباعها وتقيدها

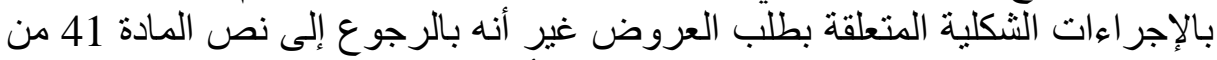

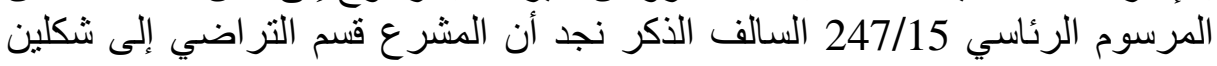
هما التراضي البسيط و التر اضي بعد الاستشارة.

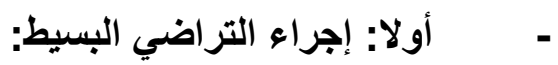

نصت المادة 49 من المرسوم الرئاسي 247/15 على ستة حاءلات الإنيط لإمكانية اللجوء إلى

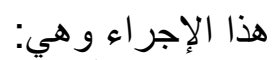

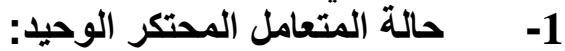
هذا باعتبار أن الخدمة التي تتطلبها التها الإدارة المتعاقدة لا يلبيها إلا مؤسسة احتكارية و واحدة. 2- الة الاستعجال الملح:

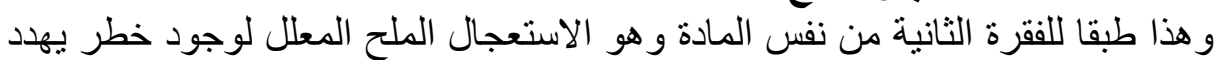

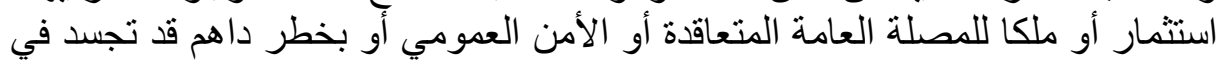

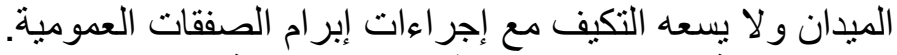

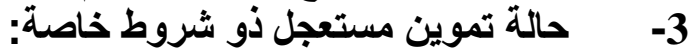

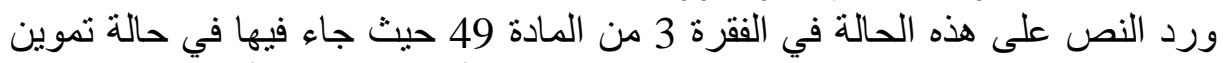

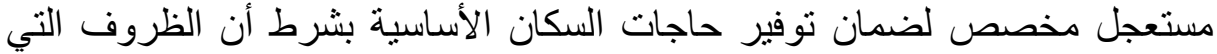

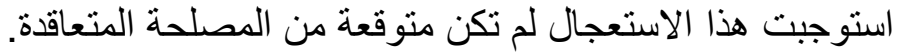

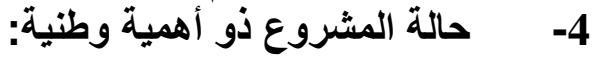

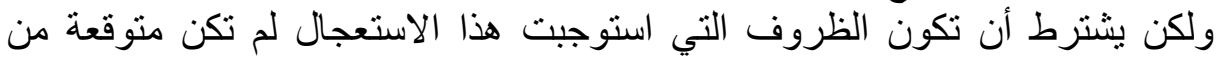

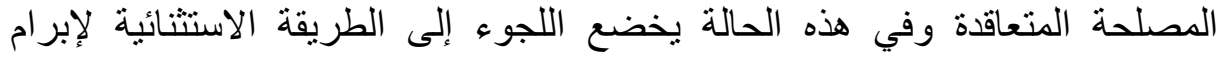

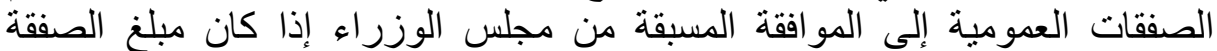

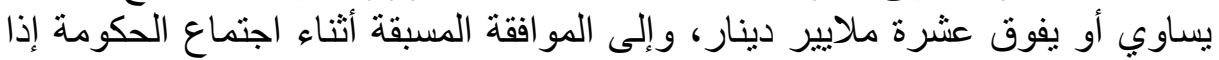

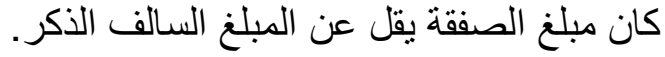


5- عندما يتعلق الأمر بترقية الأداة الوطنية العمومية للإنتاج:

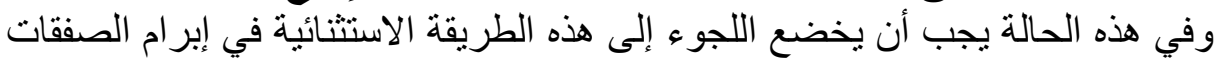

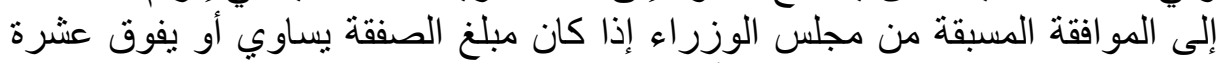

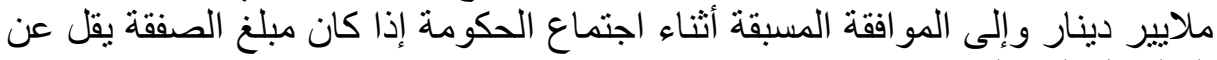

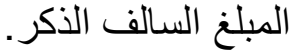

\section{6- عندما يتعلق الأمر بنص تشريعي أو تنظيمي:}

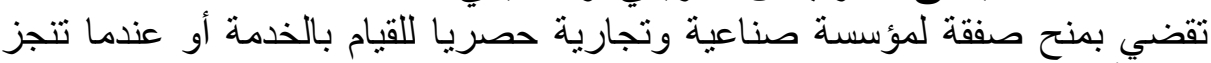
هذه الأخيرة كل نشاطها مع الهيئات الإدارية العمومية ذات الطابة الطيع الإداري.

\section{ثانيا: إجراء التراضي بعد الاستشارة:}

ونصت على هذا الإجراء المادة 51 من المرسوم الرئاسي الأسي 247/15 وذلك ضمن 5

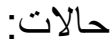

1- عندما تعين عدم جدوى طلب العروض للمرة الثانية حيث أن المصلحة

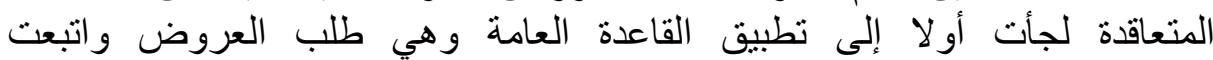

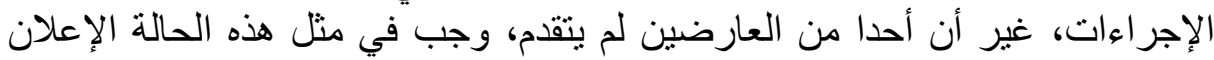

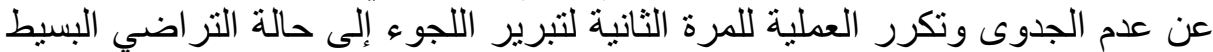

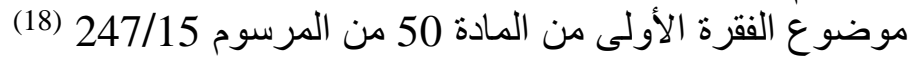

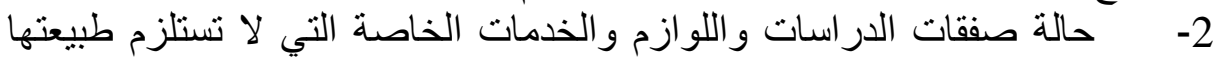

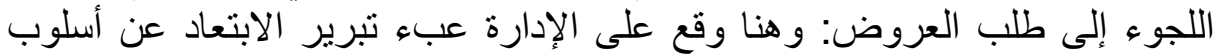

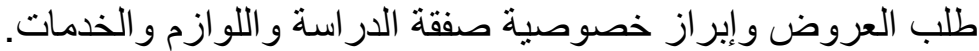
3- صفقات الأشغال التابعة لمؤسسات وطنية سيادية:

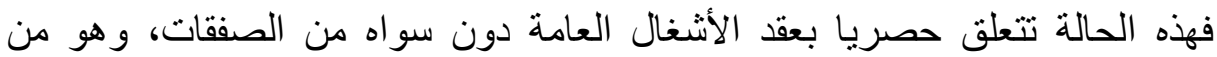
العقود التي تتضمن عنصر الزمن، وقد ورد ذكر هذه الحالة بصفقة مطلقة بدون تحديد

4- الصفقات الممنوحة التي كانت محل فسخ وكانت طبيعتها لا تتلاءم مع آجال طلب عروض جديدة: وتعتبر هذه الحالة من مستجدات المرسوم 247/15 (19)وهي حالة موضوعية تبرر

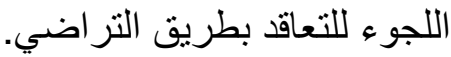

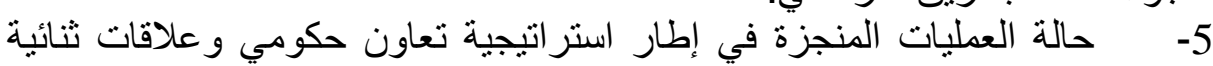

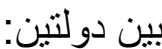

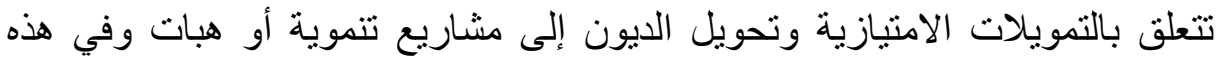

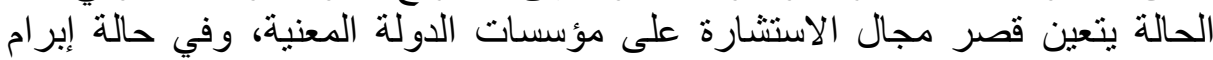

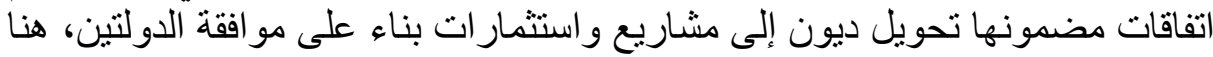

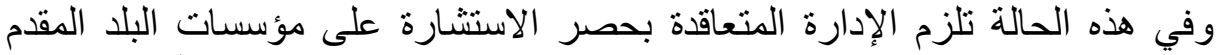

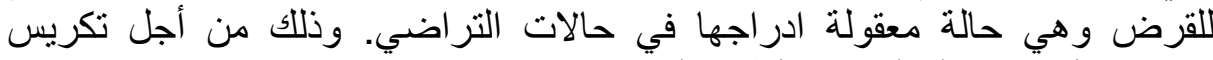
و احتر ام التز أمات الدولة ذات دات الطابع الخأرجي.

$$
\text { المبحث الثاني: إجراعات إبرام الصفقات العمومية: }
$$

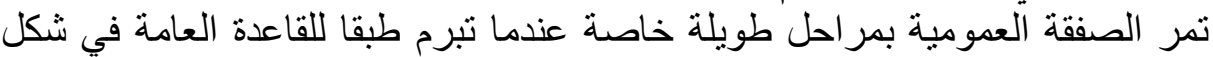

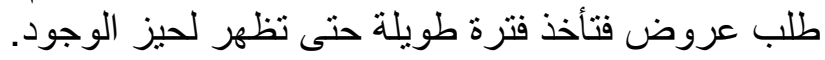

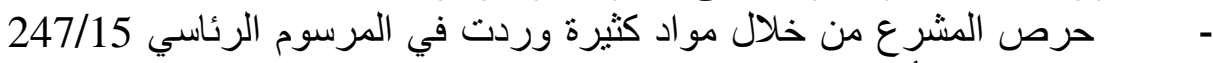

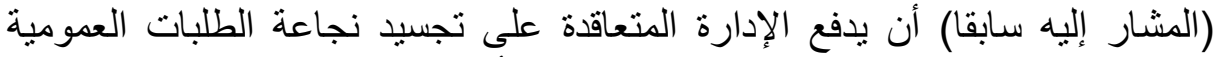

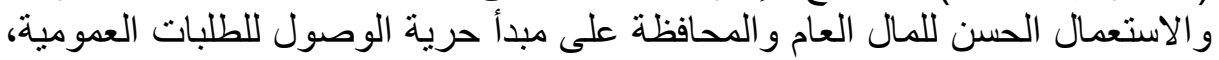


وتحقيق المساو اة بين العارضين، وشفافية المعاملة العقدية، وهي مبادئ ورد ذكرها في المادة 05 من المرسوم الجديد.

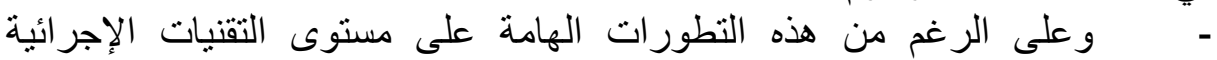

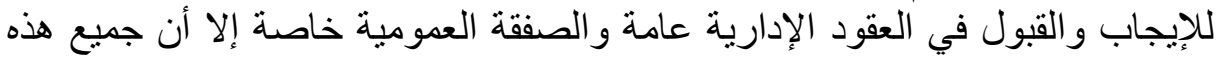

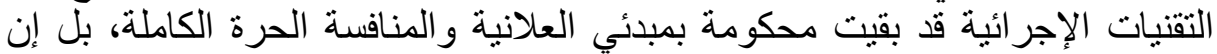

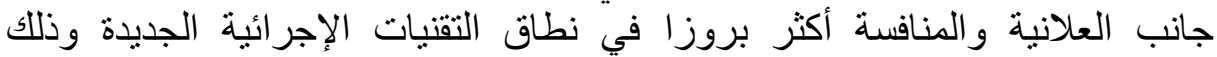
لتمتعالإدارة بسلطة تقديرية واسعة في الانتقاء.

المطلب الأول: إجراءات طلب العروض:

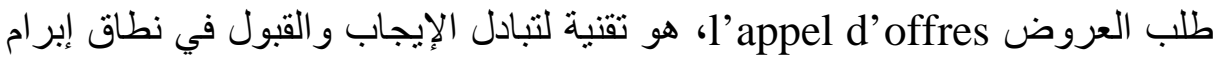

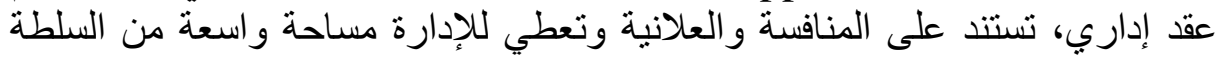

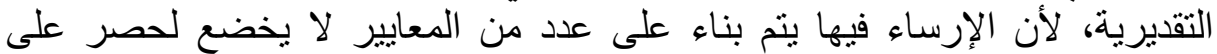
خلاف أسلوب المناقصة الذي يخضع إلى الفي معيار السعر فقط.

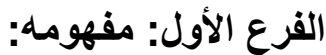

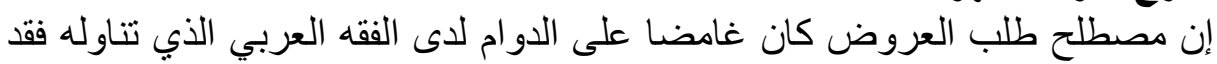

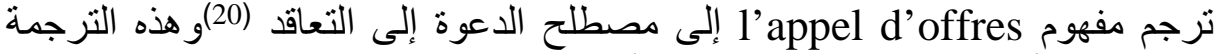

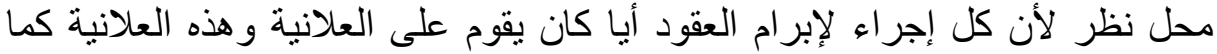

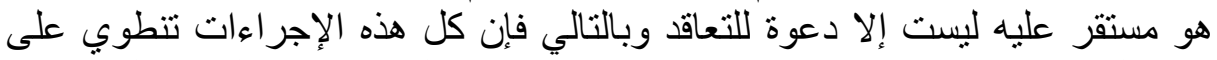

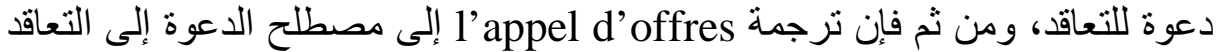

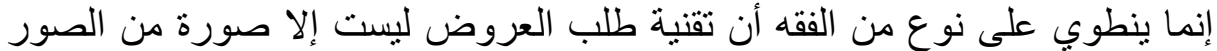

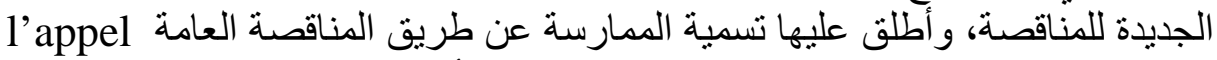

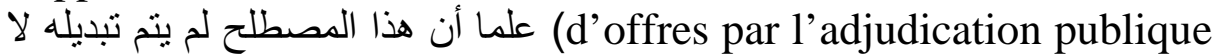
قانونا ولا قضاء ولا فقها في فرنسا منذ ظهور مصطلح l'appel d’offres وحتى كنى

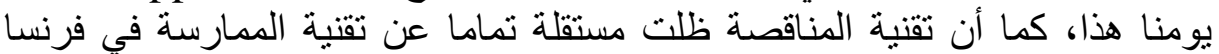

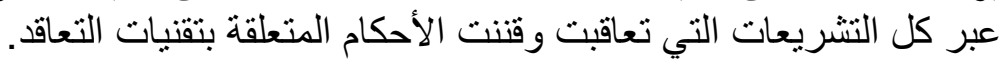

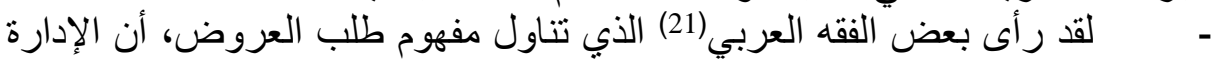

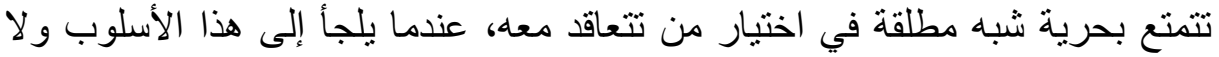

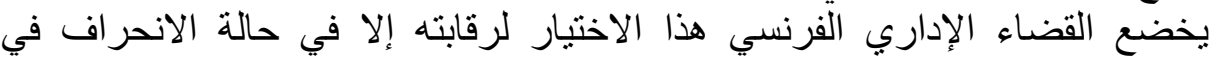

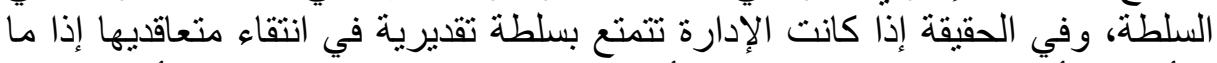

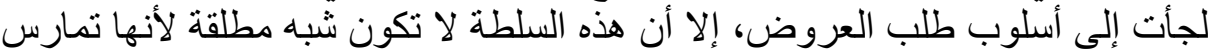

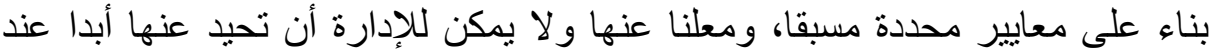

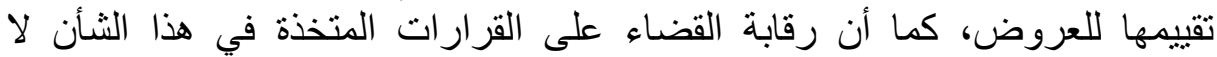

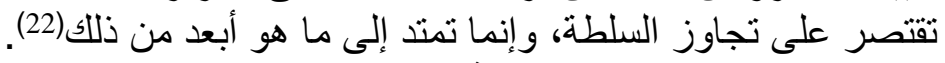

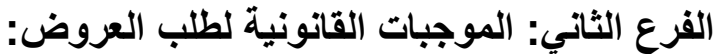

إذا كان طلب العروض إجراء يستهدف الحصول على على عدة عروض في متعهدين

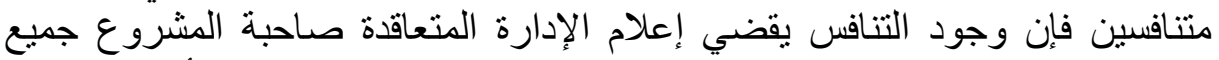

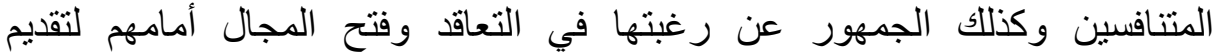

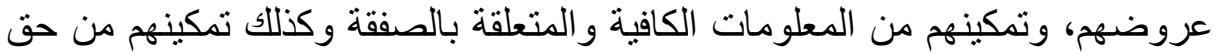
الطعن، و إذا كان المشرع قد خول جهة الإدارة إبرام العقود بالاعتر اف لهال العا بالثخصية

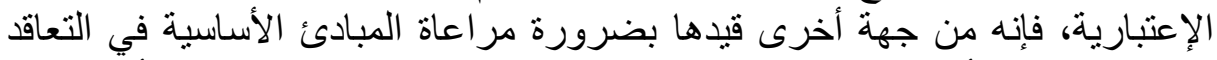

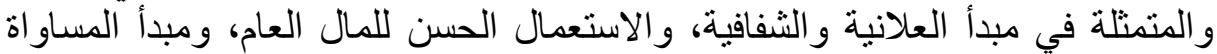

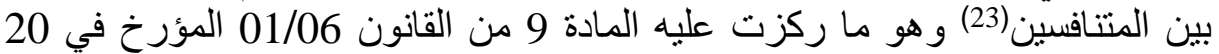

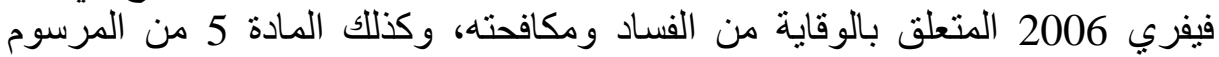

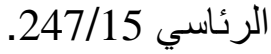




$$
\text { الفرع الثالث: أشكال طلب العروض: }
$$

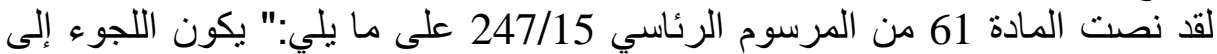
الإشهار الصحفي إلزاميا في الحالات الآنتية:

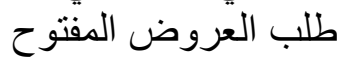

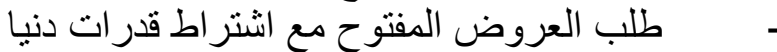

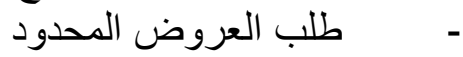
المسابقة

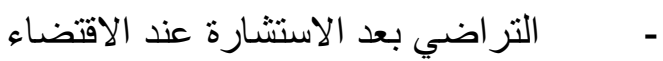

من النص أعلاه يتضح أن المشرع فرض اللجوء إلى الإشهار بنشر إعلان طلب التبان

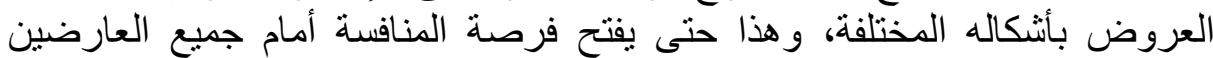
ويجسد مبدا علنية وشفافية الصفقة، وكذلك مبدا المساواة بين المتنافسين، هذه المبادئ التئ

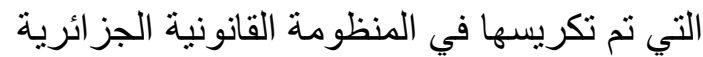

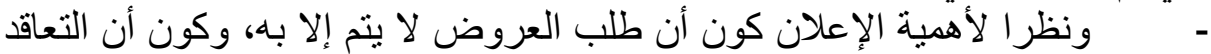

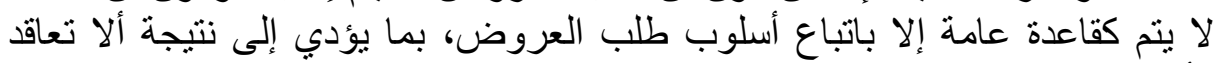

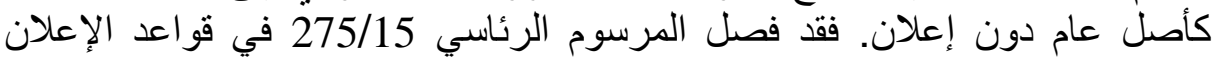

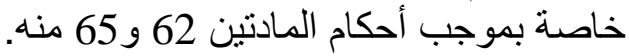

الفرع الرابع: مراحل الصفقة العمومية:

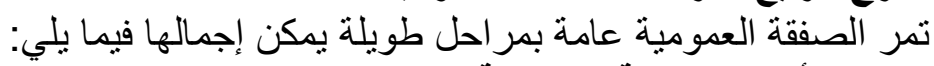

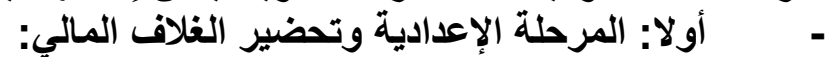

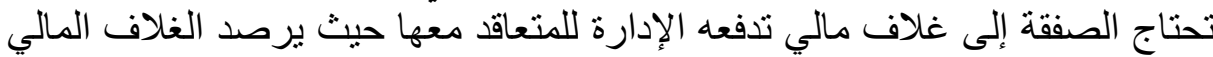

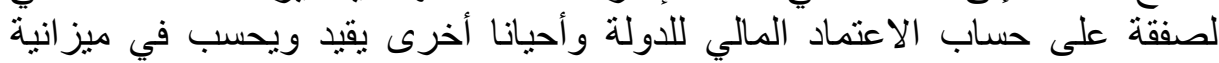

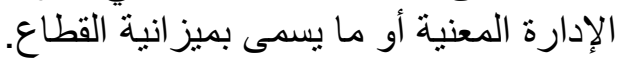

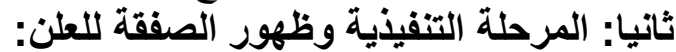

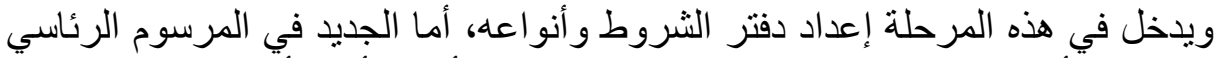

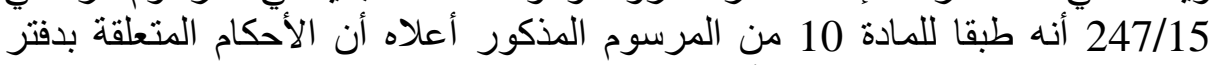

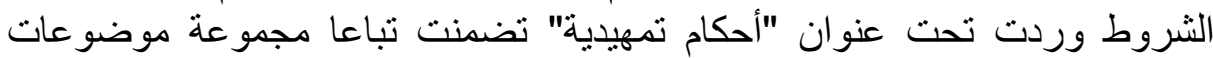

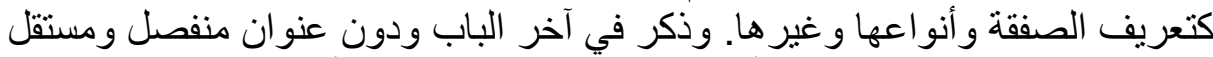

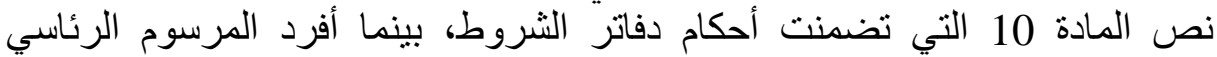

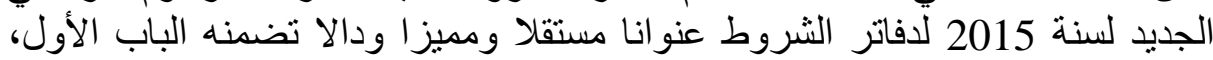

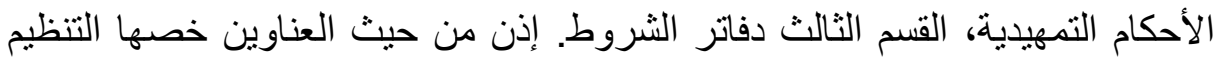

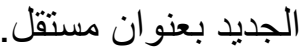

\section{ثالثا: مرحلة الإعلان في الجرائد ونشرة الصفقات العمومية:}

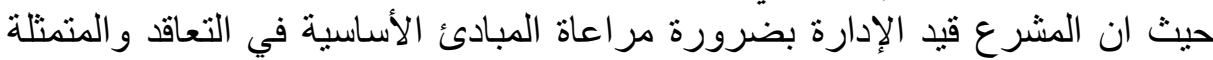

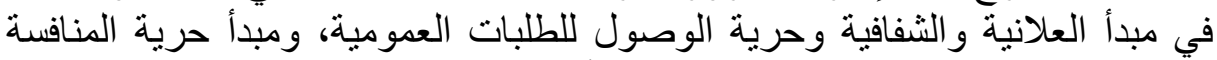
الثريفة، الاستعمال الحسن للمال العام، ومبدأ المساو اة بين المتنافسين(24).

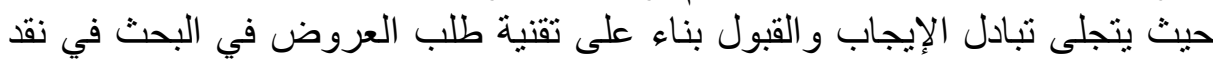

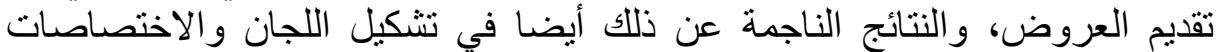
المنوطة بها.

$$
\text { رابعا: مرحلة إيداع العروض: بلمان }
$$

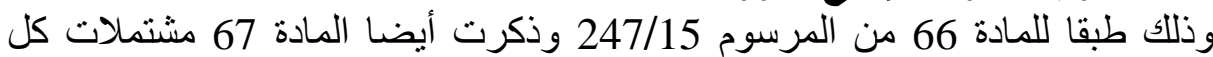

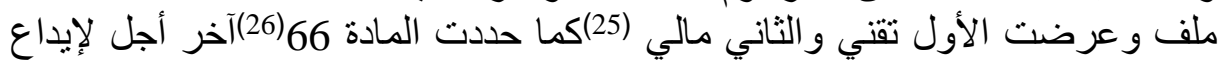

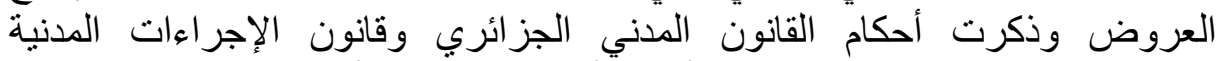
والإدارية كيفية احتساب الآجال ومن أين تبدأ ويوم انقضناء الأجل. 


\section{خامسا: مرحلة فتح الأظرفة وتقييم العروض:}

أسندت نصوص تتظيم الصفقات العمومية الجزائرية مهرة فتهمة فتح الأظرفة وفحص

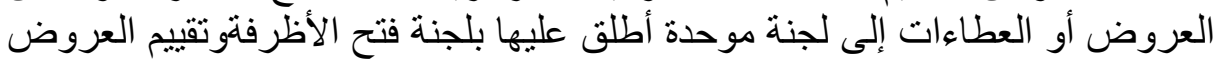
وذللك طبقا لأحكام المو اد 71، 160، 162، 71 من المرسوم 247/15

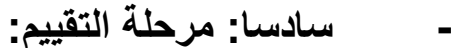
وذللك طبقا لأحكام المادة 72 التي حددت المهاء المهام التي يجب أن تمارس من قبل لجنة

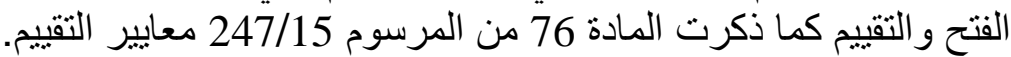

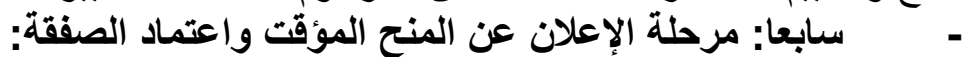

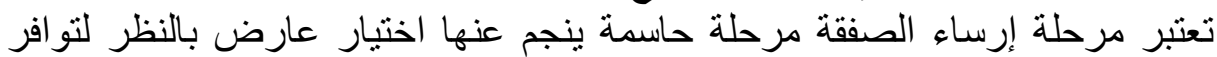

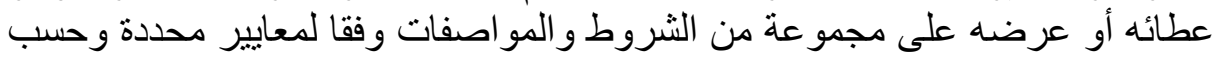

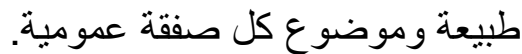

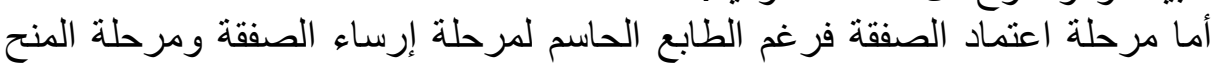

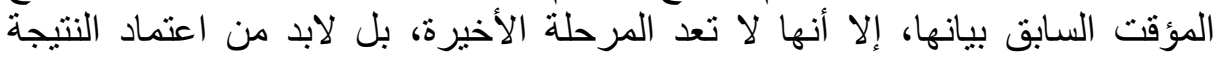

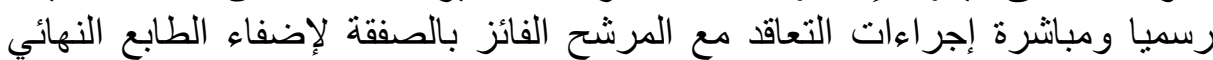

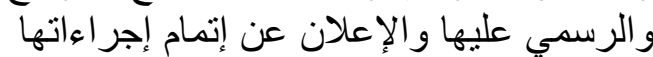

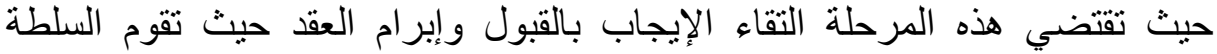

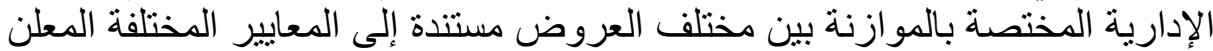

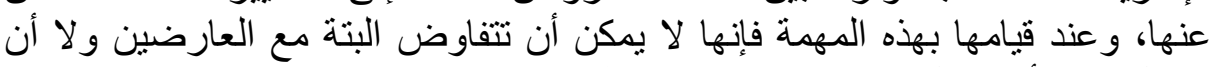

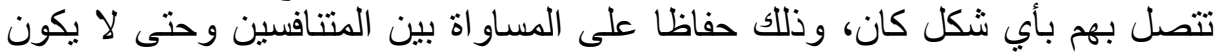

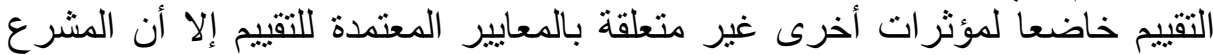

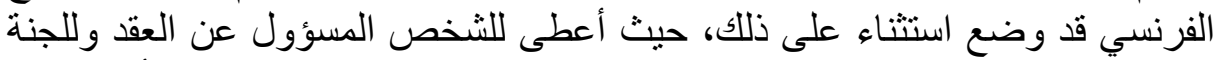

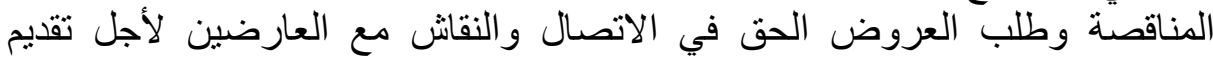

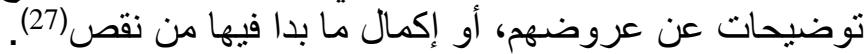

$$
\text { المطلب الثاني: أسلوب التراضي: - n }
$$

إذا كان الأصل في غالبية العقود الإدارية أن القانون يرسم طريقا محددا لتبادل

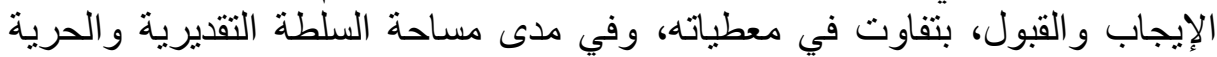

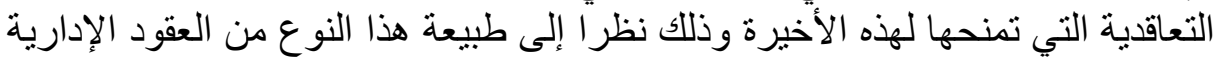

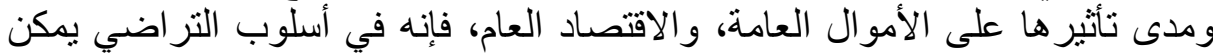

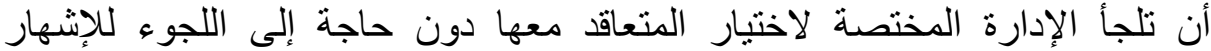

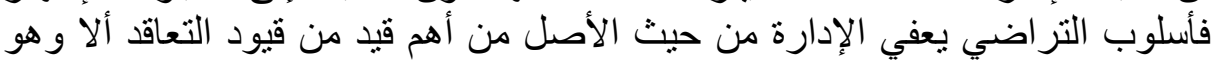

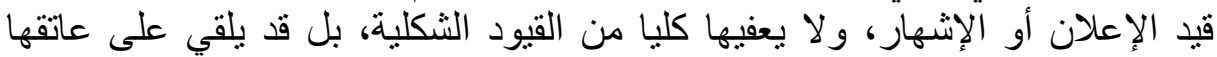

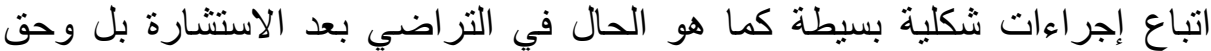

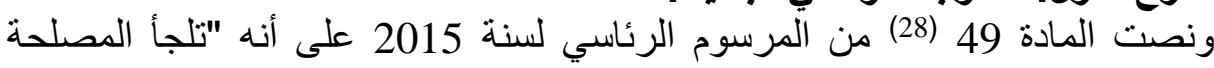

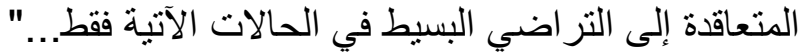

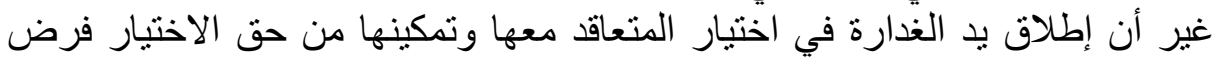

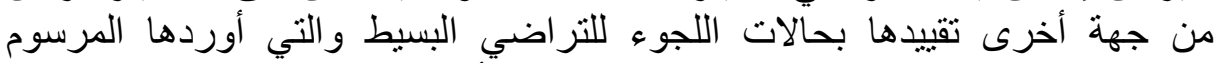
الرئاسي حالة بحالة فلا تستطيع الإدارة المتعاقدة أن تختار المتعامل مباشرة وداثي ودون

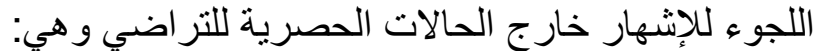
1 - الة المشروع ذي أهمية وطنية -2 - - عندما يتعلق الأمر بترقية الأداة الوطنية العمومية للإنتاج 
3- عندما بتعلق الأمر بنص تشريعي أو تتظيمي بقضي بمنح صفقة لمؤسسة

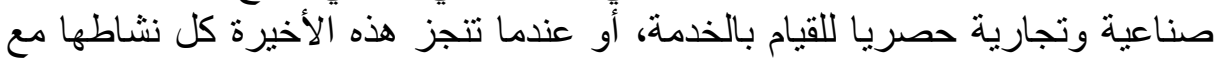

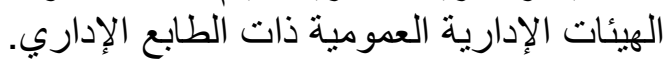
الفرع الثاني: أسلوب التراضي التبدي بعد الاستشارة:

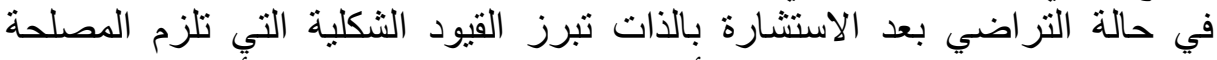

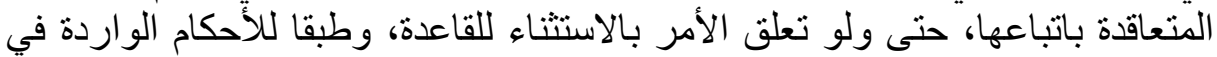

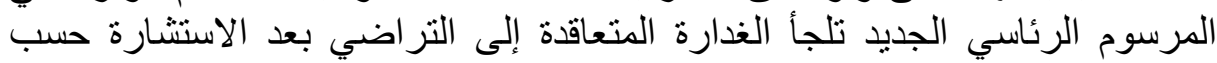
المادة 5(29) منه في الحالي الجيات التالية:

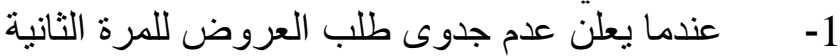

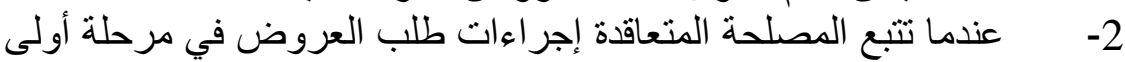

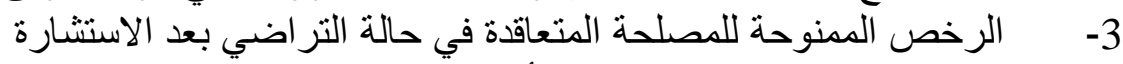
وفي حال اتباع المصلحة المتعاقدة لهذا الأسلوب يمكنها قانونا: ـ أن تقلص من مدة تحضير العروض طبقا لأحكام المادة 52 من المانيأ المرسوم

4- حالة صفقات الدر اسات و اللو ازم و الخدمات الخاصة التي لا تستلزم طبيعتها

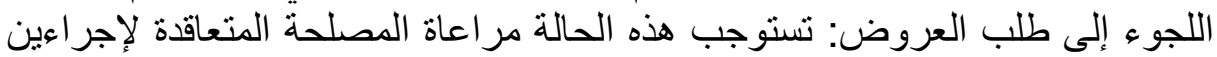
جو هريين هما:

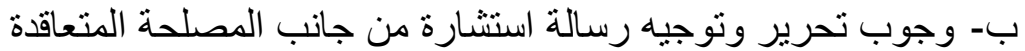
5- بالنسبة لصفقات الأشغال التابعة لمؤسسات وطنية سيادية: وتستوجب هذه الحالة مر اعاة المصلحة المتعاقدة للإجر اعين جو هربين:

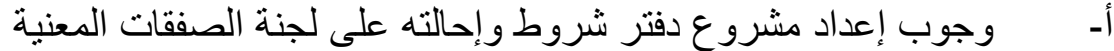

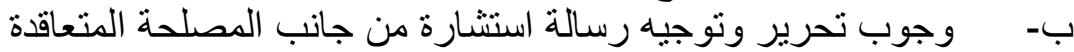

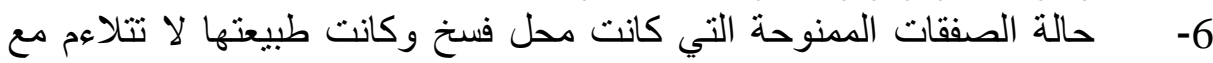
آجال طلب عروض جديدة 7- حالة العمليات المنجزة في إطار استراتيجية تعاون حكومي وعلاقات ثنائية

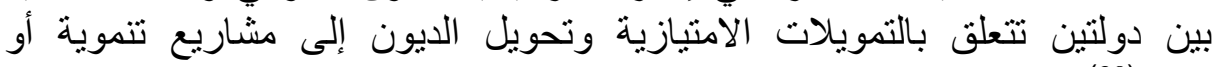

من خلال ما تقدم في هذا المقال نستنتج أن الإيجاب في نطاق طلب العروض يصد التهدر

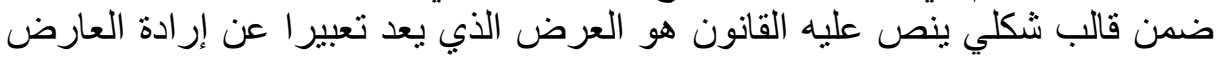

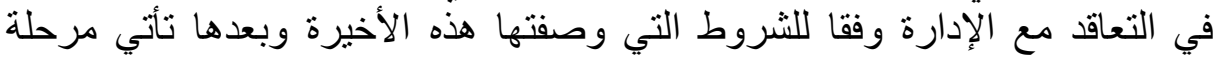
الآرساء وتوقيع العقد باعتبار هما يجسدان قبول الإدارة بعد فحصها للعروض الإن المقدمة

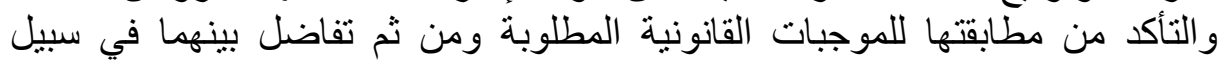
الوصول إلى العرض الأفضل الذي يجب أن يتم التعاقد مع صاحبه.

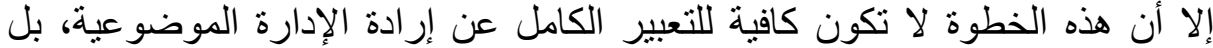

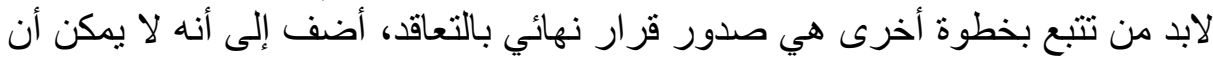

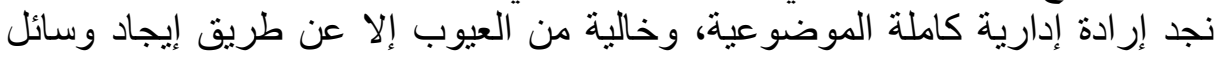
من شأنها أن تدعم من شفافية حركة الإيجاب و القبول في العقود الإدارية الإية 


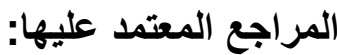

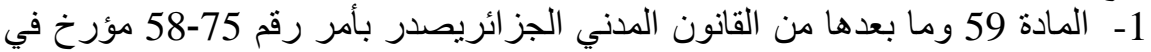
20 رمضان عام 1395 الموافق 26 سبتمبر سنة 1975 يتضدن الفئرن القانون المدني معدل ومتمح.

2- المادة 4 من المرسوم الرئاسي 15/247 المؤرخ في 16 سبتمبر سنة 2015 المتعلق

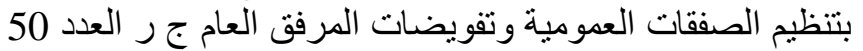

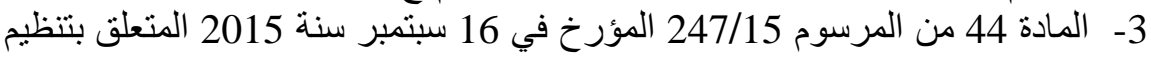

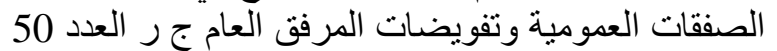

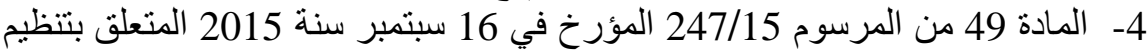

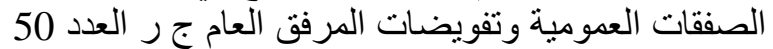

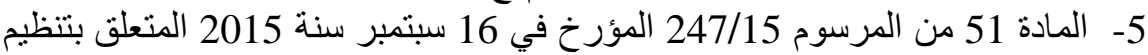

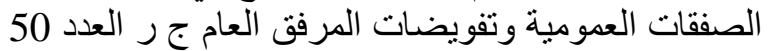

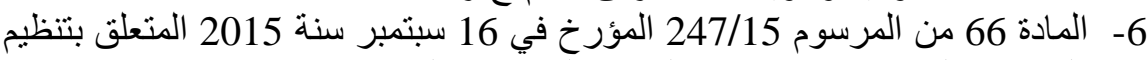

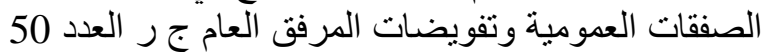

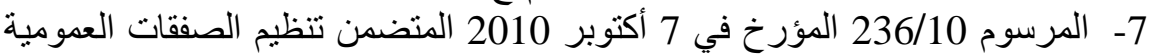

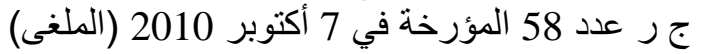

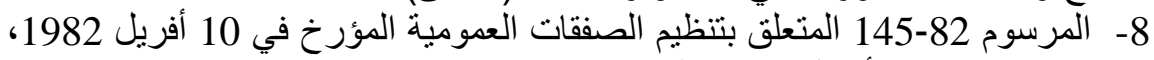

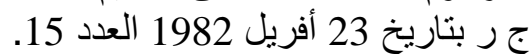
9- مهند مختار نوح، الإيجاب و القبول في العقد الإداري، منشور ات الحلبي الحقوقية، ص 496 10-سليمان الطماوي، الأسس العامة للعقود الإدارية، مطبعة جامعة عين شمس، القاهرة

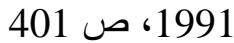

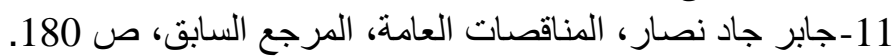

12-عبد الحميد كمال حشيش، التطور الحديث للمبادئ العامة للعقود الإدارية، المرجع السابق، ص الخ 108.

13-عبد الغني بسيوني عبد الله، القانون الإداري، بيروت، الدار الجامعية للطباعة

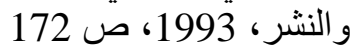
14-محمود خلف الجبوري، العقود الإدارية، الطبعة الثنانية، مكتبة دار الثقافة للنشر

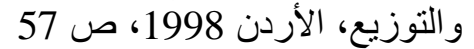

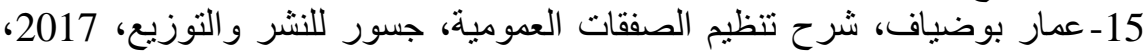
ص 305 وما يليها.

16-AUBERT J.C, Notions et rôles de l'offre et l'acceptation dans la formation du contrat LGDT,paris,1970 p 16.

17-CE 18-11-1991 le chaton/c/commune de guidel,D,1992 p 187.

18-Flamme MA Traite des marches publics,T1,P 181.

19-l'aubadére- delvolve et moderne, traité des contrats administratifs, op cit p 656

20-Philippe Shmidt, Laure Thierry, le point sur les marchés a procédure adaptée, p 105.

1الهوامش: عدد 58 المؤرخة في 7 أكتوبر 23610 الرون 2010 (الملغى) 2) 4 من المرسوم الرئاسي 15/247 المؤرخ في العي 16 سبتمبر سنة 2015 المنتعلق بتنظيم الصفقات العمومية وتفويضات المرفق العام جر العر العدد 50

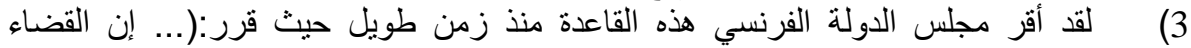

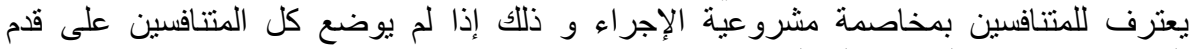

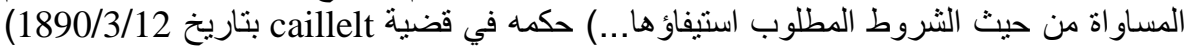




$$
\begin{aligned}
& \text { والمجموعة ص 321، منقول عن مرجع مهند مختار نوح، الإيجاب والقبول في العقد الإداري، }
\end{aligned}
$$

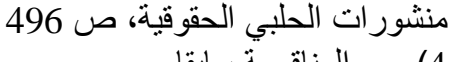

$$
\begin{aligned}
& \text { 4) المناقصة سابقا }
\end{aligned}
$$

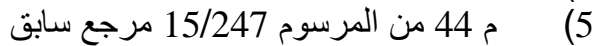

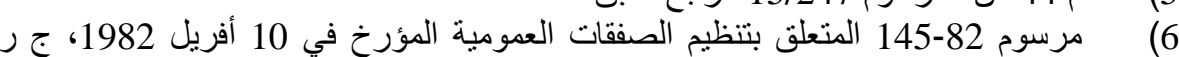

$$
\begin{aligned}
& \text { بتاريخ } 23 \text { أفريل } 1982 \text { العدد } 15 \text { مبرم }
\end{aligned}
$$

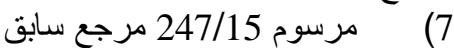

$$
\begin{aligned}
& \text { 8) مهند مختار نوح: الإيجاب والقبول في العقد الإداري، منشورات الحلبي الحقوقية، طبعة } \\
& \text { 2005، ص } 609
\end{aligned}
$$

9) AUBERT J.C, Notions et rôles de l'offre et l'acceptation dans la formation du contrat LGDT,paris,1970 p 16.

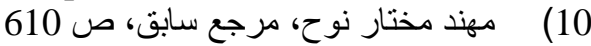

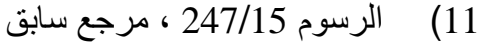

$$
\begin{aligned}
& \text { 12 ) م } 59 \text { وما بعدها من القانون المدني الجز ائري الإدار } \\
& \text { 13) سليمان الطماوي، الأسس العامة للعقود الإدارية، مطبعة جامعة عين شمس، القاهرة }
\end{aligned}
$$

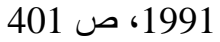

14) CE 18-11-1991 le chaton/c/commune de guidel,D,1992 p 187.

$$
\text { منقول عن مرجع مهند مختار ، المرجع السابق، ص } 220
$$

15) Flamme MA Traite des marches publics,T1,P 181.

16) l'aubadére- delvolveet moderne, traité des contrats administratifs, op cit p 656

17) la dispense de mise en concurrence, une possibilité confinée sans le contexte de généralisation de principes jurisprudentiels qui la sous-tendent et de multiplication des textes qui l'imposent, la mise en concurrence et une exigence qui ne peut être écartée que si elle est incompatible avec l’objectif poursuivi par l'achat de telles situations sont nécessairement exceptionnelles et devants pouvoir être sérieusement justifiées par l'acheteur Philippe Shmidt, Laure Thierry, le point sur les marchésa procédure adaptée, p 105.

$$
\begin{aligned}
& \text { 18) م 40،51،52 من المرسوم 247/15، مرجع سابق. }
\end{aligned}
$$

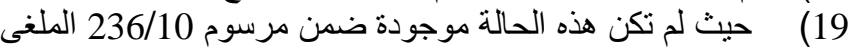

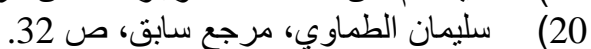

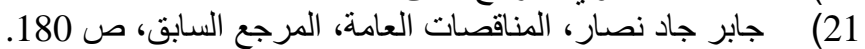

$$
\begin{aligned}
& \text { 22) عبد الحميد كمال حشيش، التطور الحديث للمبادئ العامة للعقود الإدارية، المرجع السابق، } \\
& \text { ص } 108 . \\
& \text { 23) عبد الغني بسيوني عبد الله، القانون الإداري، بيروت، الدار الجامعية للطباعة والنشر، } \\
& \text { 1993، ص صن الفي } 172
\end{aligned}
$$

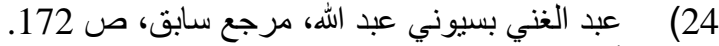

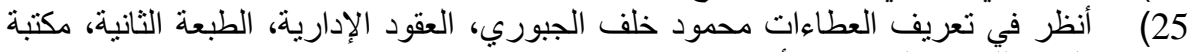

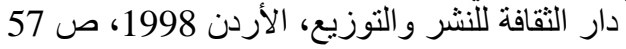

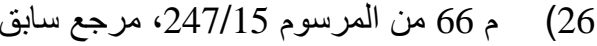

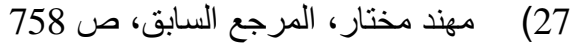

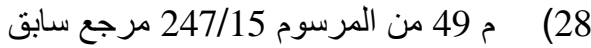

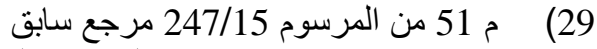

$$
\begin{aligned}
& \text { 30) عمار بوضياف، شر ح تنظيم الصفقات العمومية، جسور للنشر والتوزيع، 2017، ص صر } 305 \\
& \text { وما يليها. }
\end{aligned}
$$

